\title{
Rat Anterior Pituitary
}

\section{DISTINCTION OF AN 8S, CORTICOSTERONE-PREFERRING SPECIES FROM DEXAMETHASONE-BINDING GLUCOCORTICOID RECEPTORS}

\author{
Zygmunt S. Krozowski and John W. Funder, Medical Research Centre, Prince \\ Henry's Hospital, Melbourne, 3004, Australia
}

A B S T R A C T Studies on the feedback inhibition of ACTH release by steroid hormones and on the binding of tritiated steroids by the pituitary have prompted the hypothesis that receptors in addition to or other than classical glucocorticoid receptors may mediate steroid hormone effects in this tissue. Accordingly, we have asked whether more than one glucocorticoidbinding species, distinct from corticosteroid binding globulin, can be found in rat anterior pituitary gland.

In our study we have demonstrated high affinity $\left(K_{d}\right.$ $4^{\circ} \mathrm{C} \sim 1 \mathrm{nM}$ ) binding sites for tritiated corticosterone $\left({ }^{3} \mathrm{H}-\mathrm{B}\right)$ in rat pituitary cytosol, distinct from classical glucocorticoid receptors and transcortin-like sites. Unlike ${ }^{3} \mathrm{H}$-B-transcortin complexes, ${ }^{3} \mathrm{H}-\mathrm{B}$ bound to such sites is adsorbed onto hydroxylapatite and is stabilized by sulphydryl group reducing agents. Sucrose density gradient analysis in low ionic strength buffer under equilibrium conditions ( ${ }^{3} \mathrm{H}-\mathrm{B} \pm$ nonradioactive competitors throughout) showed ${ }^{3} \mathrm{H}-\mathrm{B}$ to sediment as a single, $\sim 8 \mathrm{~S}$ peak, from which ${ }^{3} \mathrm{H}-\mathrm{B}$ was consistently better displaced by $\mathrm{B}$ than dexamethasone (DM); ${ }^{3} \mathrm{H}-\mathrm{DM}$ similarly bound to an $\sim 8 \mathrm{~S}$ peak, from which it was better displaced by DM than B. The existence of two species of pituitary glucocorticoid receptors is further supported by clear differences in specificity for a range of steroids, and in the differential depletion of cytoplasmic sites after in vivo DM administration. Similar "B-preferring" sites were not found in thymus cytosols. These results demonstrate that there exist in the pituitary high affinity intracellular binding sites for naturally occurring glucocorticoids, distinct from clas-

Received for publication 6 November 1981 and in revised form 25 May 1982.

${ }^{1}$ Abbreviations used in this paper: ALDO, aldosterone; AP, anterior pituitary; B, tritiated cortisone; CBG, corticosterone binding globulin; DM, dexamethasone; DOC, desoxycorticosterone; $\mathrm{P}$, progesterone; $\mathrm{TA}$, triamcinolone acetonide. sical glucocorticoid receptors and transcortin-like sites. Physiological roles as glucocorticoid receptors remain to be established for these B-preferring sites.

\section{INTRODUCTION}

It has been shown in both experimental animals (1) and human (2) studies that after the administration of glucocorticoids there are two periods of inhibition of stress-induced ACTH release, an immediate or "fast feedback" effect, and a "delayed feedback" effect occurring an hour or more after steroid administration. There is also evidence that fast and delayed feedback effects on ACTH release are differentially effected by a range of steroids $(1,3)$, presumably mediated by a heterogenous population of glucocorticoid binding sites $(2,3)$.

In vivo and in vitro studies have suggested that the anterior pituitary may have cellular mechanisms for recognizing and responding to glucocorticoids distinct from those generally operative in other tissues. McEwen and his co-workers have shown tritiated corticosterone $\left({ }^{3} \mathrm{H}-\mathrm{B}\right)$ to be negligibly bound by pituitary nuclei in comparison with tritiated dexamethasone $\left({ }^{3} \mathrm{H}-\mathrm{DM}\right)(4,5)$. Intracellular or membrane bound CBG-like ${ }^{3} \mathrm{H}-\mathrm{B}$ sequestering sites have been proposed to account for this difference (6-8). However, despite the apparently very low levels of corticosterone retained in the nucleus, this steroid has been shown to suppress ACTH secretion from cultured mouse pituitary tumor AtT-20 cells (9). The comparable potencies of $B$ and DM in suppressing ACTH secretion suggest that the fast feedback effect may not be modulated via the classical glucocorticoid receptor $(2,9)$. Finally, progesterone, a predominant or full antagonist in other classical glucocorticoid effector systems (10-14), appears to be a full agonist in terms of this fast suppression of ACTH both in the rat anterior pituitary gland (1) and AtT-20 cells (9).

In previous studies, Harrison and co-workers have 
shown ${ }^{3} \mathrm{H}$-triamcinolone acetonide to bind to two classes of sites in AtT-20 cell cytosol; these sites are distinguishable on the basis of kinetics and specificity (15). Our study was designed to determine whether corticosterone binds to sites in the anterior pituitary distinct from the classical, ${ }^{3} \mathrm{HDM}$ binding glucocorticoid receptors (10), corticosteroid binding globulin (CBG)-like, putative "type III glucocorticoid receptors" (16), or other CBG-like intracellular glucocorticoid sequestering sites $(6,7)$. Crucial to such a distinction has been the use of sucrose density gradient equilibrated with radiolabeled steroid, with or without competitors, throughout the gradient, and the use of hydroxylapatite to separate CBG-like binding sites from other steroid binding sites. On the basis of our findings we would postulate the existence-in the pituitary but not the thymus-of a novel, nonclassical, B-preferring $8 \mathrm{~S}$ binding species, distinct from the classic glucocorticoid receptor.

\section{METHODS}

${ }^{3} \mathrm{H}-\mathrm{DM}(50 \mathrm{Ci} / \mathrm{mmol})$ and ${ }^{3} \mathrm{H}-\mathrm{B}(105 \mathrm{Ci} / \mathrm{mmol})$ were purchased from New England Nuclear, Boston, MA. Nonradioactive dexamethasone was the gift of Merck, Sharp and Dohme (Sydney, Australia); other nonradioactive steroids were from Ikapharm (Ramat-Gan, Israel) and Steraloids (Wilton, NH).

In all studies female Sprague-Dawley rats, body weight 150-200 g, were used $4 \mathrm{~d}$ after adrenalectomy. In some experiments, animals were injected i.p. with $100 \mu \mathrm{l}$ saline containing various concentrations of Decadron (dexamethasone sodium phosphate) $30 \mathrm{~min}$ before sacrifice. Rats were killed by decapitation, and the thymus and anterior pituitary (AP) removed into ice-cold TEMGD buffer $(10 \mathrm{mM}$ Tris, $1.5 \mathrm{mM}$ EDTA, $20 \mathrm{mM}$ sodium molybdate, $10 \%$ glycerol (vol/vol), $2 \mathrm{mM}$ dithiothreitol, $\mathrm{pH}$ 7.4). Tissues were lightly teased and thoroughly washed in buffer before homogenization. All procedures were carried out at $4^{\circ} \mathrm{C}$.

For sucrose gradient analyses five anterior pituitaries were homogenized (glass/glass) in $200 \mu \mathrm{l}$ TEMGD buffer, and a high-speed supernatant prepared by centrifuging the homogenate at $200,000 \mathrm{~g}$ for $40 \mathrm{~min}$ at $4^{\circ} \mathrm{C}$. Cytosols were incubated with $100 \mu \mathrm{l}$ TEMGD buffer containing ${ }^{3} \mathrm{H}-\mathrm{B}$ or ${ }^{3} \mathrm{H}-\mathrm{DM}$ in the presence or absence of competing steroid for $4 \mathrm{~h}$ at $4^{\circ} \mathrm{C}$. Aliquots $(300 \mu \mathrm{l})$ were placed on top of $6-\mathrm{ml}$ density gradients (5-20\% sucrose) prepared in TEMGD buffer containing the appropriate steroids throughout, and centrifuged for $18 \mathrm{~h}$ at $220,000 \mathrm{~g}$ at $4^{\circ} \mathrm{C}$ in a Beckman L565 ultracentrifuge (Beckman Instruments, Inc., Fullerton, CA). Gradients were fractionated with a peristaltic pump; fractions $(\sim 250 \mu \mathrm{l})$ were collected directly into plastic tubes on ice. Bound and free steroids were separated by the addition of $300 \mu \mathrm{l}$ of an ice-cold suspension of hydroxylapatite $(15 \% \mathrm{wt} / \mathrm{vol})$ in buffer $\mathrm{B}(50 \mathrm{mM}$ Tris, $10 \mathrm{mM}$ potassium dihydrogen phosphate, $\mathrm{pH} \mathrm{7.2)}$. After incubation for $20 \mathrm{~min}$ at $4^{\circ} \mathrm{C}$ with intermittent shaking, the tubes were centrifuged $(1,000 \mathrm{~g}, 5 \mathrm{~min})$, the supernatant aspirated, and the pellet washed $(3 \times 1 \mathrm{ml})$ with buffer $\mathrm{A}(10 \mathrm{mM}$ Tris, $5 \mathrm{mM}$ sodium dihydrogen phosphate, $1.5 \mathrm{mM}$ EDTA, $\mathrm{pH} 7.2$ ) containing $1 \%$ Tween 80 . Washed hydroxylapatite pellets were resuspended in $2 \mathrm{ml}$ ethanol, incubated at room temperature for $15 \mathrm{~min}$, centrifuged $(1,000 \mathrm{~g}, 5 \mathrm{~min})$ and the supernatant taken for liquid scintillation spectrometry.
Competition studies were performed on AP cytosol (1 AP/ $300 \mu \mathrm{l}$ TEMGD buffer) and thymus cytosol ( 1 thymus/ $8 \mathrm{ml}$ TEMGD buffer) prepared as above. Cytosol $(100 \mu \mathrm{l})$ was added to $50 \mu \mathrm{l}$ TEMGD buffer containing $40 \mathrm{nM}{ }^{3} \mathrm{H}-\mathrm{B}$ or ${ }^{3} \mathrm{H}$-DM, plus $50 \mu \mathrm{l}$ TEMGD buffer either alone or with various concentrations of competing steroid. Incubation was for $16 \mathrm{~h}$ at $4^{\circ} \mathrm{C}$. Scatchard analysis of ${ }^{3} \mathrm{H}$-B binding in pituitary cytosol was performed using $0.2-113 \mathrm{nM}{ }^{3} \mathrm{H}-\mathrm{B}$ in the presence and absence of $10 \mu \mathrm{M}$ B; specific binding was calculated as the difference between binding in the presence and absence of excess B. Bound and free steroid was separated using hydroxylapatite as described above. In those experiments in which animals were injected with DM before death, the tissue to buffer ratio was doubled at the homogenization step. An equal volume of dextran-coated charcoal ( $0.5 \%$ charcoal, $0.05 \%$ dextran) in TEMGD buffer was then added, and the suspension allowed to stand at $4^{\circ} \mathrm{C}$ for $20 \mathrm{~min}$ before centrifugation at $200,000 \mathrm{~g}$ for $40 \mathrm{~min}$ at $4^{\circ} \mathrm{C}$.

Studies on the sulphydryl group dependence of glucocorticoid binding sites were performed as follows. AP were pestle homogenized in TEMG buffer (TEMGD buffer, dithiothreitol omitted), and aliquots of the homogenate immediately brought to various concentrations of dithiothreitol. Pituitary cytosols were incubated overnight at $4^{\circ} \mathrm{C}$ with 10 $n M{ }^{3} \mathrm{H}-\mathrm{B}$ or $10 \mathrm{nM}{ }^{3} \mathrm{H}-\mathrm{DM}$, in the presence and absence of $1,000 \mathrm{nM} \mathrm{B}$ or DM, respectively, bound and free steroid separated using hydroxylapatite, and the specific binding determined per milligram protein. A parallel experiment was performed using plasma from 4-d adrenalectomized rats. Plasma was diluted 1:50 with TEMG buffer containing various amounts of dithiothreitol. Aliquots $(100 \mu \mathrm{l})$ of diluted plasma were incubated overnight at $4^{\circ} \mathrm{C}$ with $10 \mathrm{nM}{ }^{3} \mathrm{H}-\mathrm{B}$ in the presence and absence of $1,000 \mathrm{nM} \mathrm{B}$; bound and free steroids were separated by the addition of an equal volume of dextran coated charcoal suspension in TEMG buffer. After incubation at $4^{\circ} \mathrm{C}$ for 20 min the mixture was centrifuged $(800 \mathrm{~g}, 10 \mathrm{~min})$ and aliquots of the supernatant taken for liquid scintillation spectrometry.

Groups of rats (four per group) were also injected with various amounts of DM in $100 \mu \mathrm{l}$ saline i.p. After $30 \mathrm{~min}$ the animals were killed and the anterior pituitaries were pooled and homogenized in $700 \mu$ l TEMGD buffer. The crude homogenates were treated with an equal volume of dextran-coated charcoal, and cytosols prepared as above. Specific binding of ${ }^{3} \mathrm{H}-\mathrm{B}$ and ${ }^{3} \mathrm{H}-\mathrm{DM}$ was determined as described in studies on sulphydryl group dependence. Protein determinations in all studies were performed using the Bradford method (17).

Thin-layer chromatography was used to determine the extent of metabolism of ${ }^{3} \mathrm{H}-\mathrm{B}$ and ${ }^{3} \mathrm{H}$-DM during the course of incubation with cytosol. Cytosols were made $10 \mathrm{nM}$ with respect to ${ }^{3} \mathrm{H}$-B or ${ }^{3} \mathrm{H}-\mathrm{DM}$, incubated overnight at $4^{\circ} \mathrm{C}$ and extracted with 2 vol of dichloromethane/methanol (5:1). The extracts were dried under nitrogen and the residues taken up in $20 \mu \mathrm{l}$ ethanol containing $20 \mu \mathrm{g} \mathrm{B}$ or DM as carrier. Chromatography was performed on silica gel coated glass plates. Samples containing ${ }^{3} \mathrm{H}-\mathrm{B}$ were run in chloroform/ ethanol (70:30), and those containing ${ }^{3} \mathrm{H}-\mathrm{DM}$ in chloroform/ ethanol (80:20). Relative mobility $\left(R_{f}\right)$ values for both steroids were 0.77 under the chromatography conditions chosen.

\section{RESULTS}

Pituitary cytosols incubated with ${ }^{3} \mathrm{H}-\mathrm{B}$ in the absence or presence of competing steroids were sedimented through sucrose gradients of an identical steroid com- 


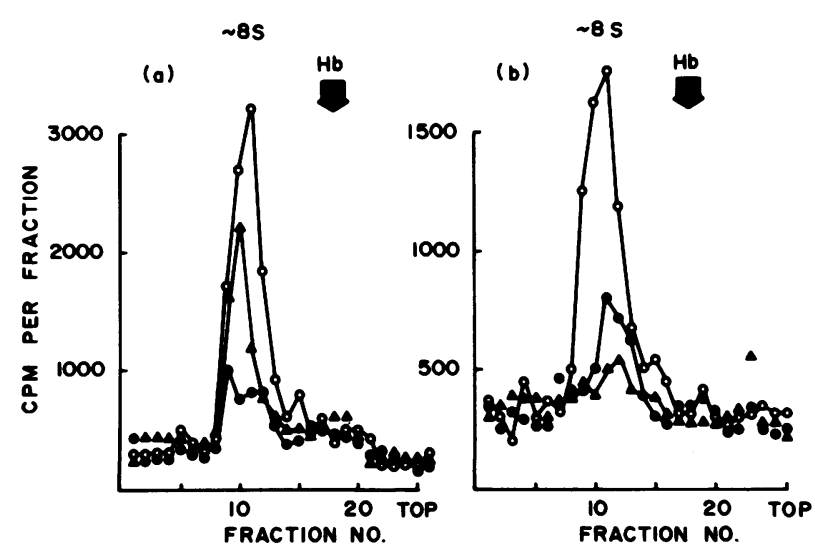

Figure 1 Sucrose gradient analysis of (a) $10 \mathrm{nM}{ }^{3} \mathrm{H}-\mathrm{B}$ binding to rat pituitary cytosol in the absence of competitor (open circles) and presence of $80 \mathrm{nM} \mathrm{B}$ (closed circles) or $80 \mathrm{nM}$ $\mathrm{DM}$ (closed triangles); (b) $10 \mathrm{nM}{ }^{3} \mathrm{H}-\mathrm{DM}$ binding in the absence of competitor (open circles) and presence of $80 \mathrm{nM}$ $\mathrm{B}$ (closed circles) or $80 \mathrm{nM}$ DM (closed triangles). Gradients contained the appropriate steroids throughout. Hydroxylapatite was used to separate the bound and free radioactivity within each fraction. Hemoglobin $(\mathrm{Hb})$, sedimenting at $4 \mathrm{~S}$, was used as an internal sedimentation marker.

position throughout as the incubation media. Hydroxylapatite was used to separate bound and free steroid in each gradient fraction. As can be seen in Fig. la, ${ }^{3} \mathrm{H}-\mathrm{B}$ was specifically bound in the $8 \mathrm{~S}$ region of the gradient under low ionic strength conditions. This peak of radioactivity was consistently more displaced by eightfold nonradioactive $B$ than eightfold nonradioactive DM. In marked contrast, the analogous experiment with ${ }^{3} \mathrm{H}-\mathrm{DM}$ (Fig. $1 \mathrm{~b}$ ) revealed that ${ }^{3} \mathrm{H}-\mathrm{DM}$, also bound in the $8 \mathrm{~S}$ region, was better displaced by $D M$ than $B$. These results are inconsistent with the thesis that ${ }^{3} \mathrm{H}-\mathrm{B}$ and ${ }^{3} \mathrm{H}-\mathrm{DM}$ share a single class of $8 \mathrm{~S}$ binding sites. The characteristics of the ${ }^{3} \mathrm{H}$-DM binding sites are consistent with those of classical glucocorticoid receptor (10); ${ }^{3} \mathrm{H}-\mathrm{B}$ binding, however, with a higher affinity for B than DM, cannot be predominantly to the classic glucocorticoid receptor. These sites are also clearly different from the rat pituitary $4 S$ CBG-like binding site (6-8), in that-in contrast with such sites-they sediment at $8 \mathrm{~S}$ under low ionic strength conditions, and can be absorbed onto hydroxylapatite. Conventional sucrose density gradient analysis showed very high levels of a $4 \mathrm{~S}^{3} \mathrm{H}-\mathrm{B}$ binding species, from which ${ }^{3} \mathrm{H}-\mathrm{B}$ could be displaced by excess $B$ but not DM. We interpret these findings as consistent with very high levels of CBG in the pituitary, and the absence of such a peak using the present technique as confirmation that hydroxylapatite does not bind CBG (18). Under nonequilibrated conditions (where no steroid was included throughout the gradient) no $8 \mathrm{~S}$ peak of ${ }^{3} \mathrm{H}-\mathrm{B}$ binding was found. This difference is consistent with a relatively rapid dissociation of ${ }^{3} \mathrm{H}-\mathrm{B}$ from
$8 \mathrm{~S}$ binding sites under such conditions. This possibility is supported by a limited series of dissociation studies, in which excess B was added to pituitary cytosol incubated overnight with ${ }^{3} \mathrm{H}-\mathrm{B}$. Under such conditions, $50 \%$ of initial binding remained after $1 \mathrm{~h}$ at $4^{\circ} \mathrm{C}$, and levels indistinguishable from nonspecific after $8 \mathrm{~h}$. That the loss in binding was not due to substantial or preferential receptor degradation over this time period is suggested by the equivalent stability of ${ }^{3} \mathrm{H}-\mathrm{B}$ and ${ }^{3} \mathrm{H}$-DM binding sites over the much longer periods $(16+h)$ of sucrose gradient analysis.

Scatchard analysis of ${ }^{3} \mathrm{H}-\mathrm{B}$ binding to pituitary cytosol is shown in Fig. 2. At ligand concentrations of $\sim 25 \%$ saturating, the bound to free ratio departs from linearity, suggesting that these sites are relatively labile under conditions of low steroid concentration. An estimate of affinity, derived from the remainder of the Scatchard plot, shows these sites to have a $K_{d} 4^{\circ} \mathrm{C}$ $\sim 5 \mathrm{nM}$. That such nonlinearity is not attributable to positive cooperativity is attested to by the slope ( $\mathrm{S}=1.19$ ) of the Hill plot (not shown).

This ability of hydroxylapatite to discriminate between $8 \mathrm{~S}$ (putative receptor) and $4 \mathrm{~S} \mathrm{CBG-like} \mathrm{binding}$ sites was used in experiments to compare and contrast ${ }^{3} \mathrm{H}-\mathrm{B}$ and ${ }^{3} \mathrm{H}-\mathrm{DM}$ binding sites. The hormonal specificity of pituitary and thymic binding sites was determined by competition studies with a variety of non-

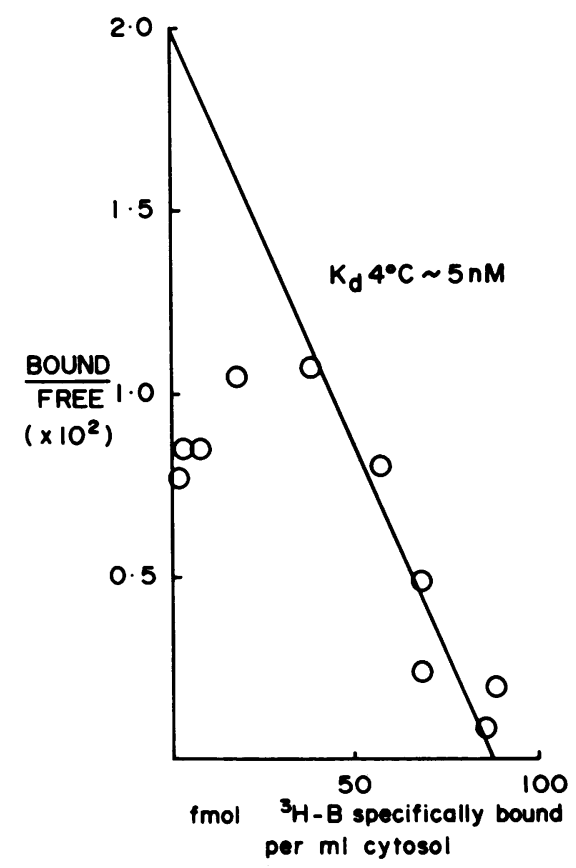

Figure 2 Scatchard analysis of ${ }^{3} \mathrm{H}-\mathrm{B}$ binding in rat anterior pituitary cytosol. Cytosol was incubated with 0.2-113 nM ${ }^{3} \mathrm{H}-\mathrm{B}$ in the presence and absence of $10 \mu \mathrm{M} \mathrm{B}$ at $4^{\circ} \mathrm{C}$ overnight. Separation of bound and free steroid was achieved using hydroxylapatite. Specific binding is plotted. 


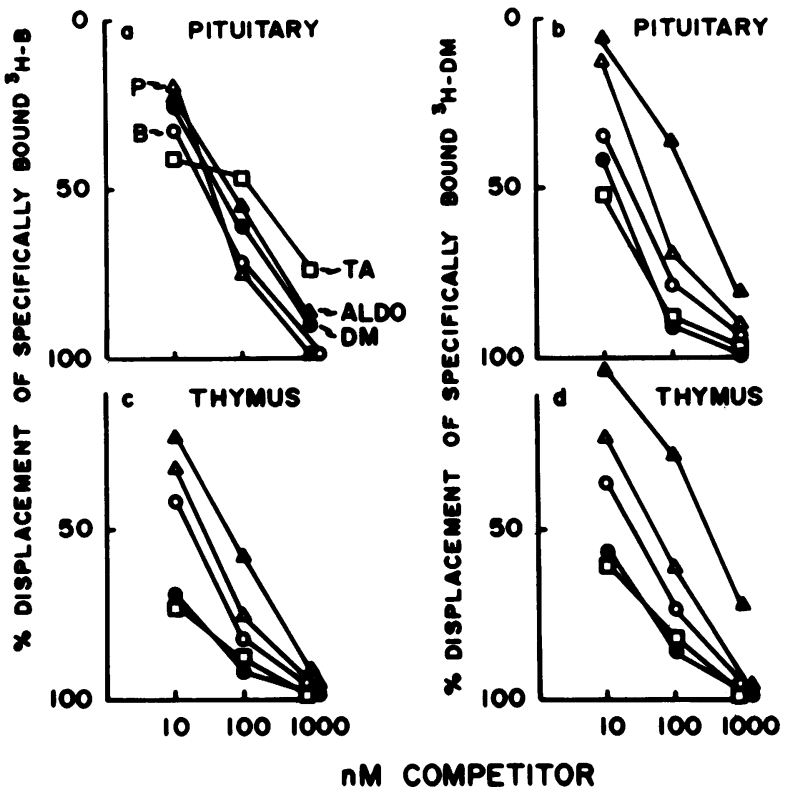

Figure 3 Steroid competition for ${ }^{3} \mathrm{H}-\mathrm{B}$ and ${ }^{3} \mathrm{H}-\mathrm{DM}$ binding sites in pituitary and thymic cytosols from adrenalectomized rats. Cytosols were incubated with $10 \mathrm{nM}^{3} \mathrm{H}-\mathrm{B}$ or $10 \mathrm{nM}$ ${ }^{3} \mathrm{H}$-DM with or without competitor at $4^{\circ} \mathrm{C}$ overnight. Competitors used were progesterone $(\mathrm{P})$, corticosterone (B), triamcinolone acetonide (TA), dexamethasone (DM) and aldosterone (ALDO). Specific binding was determined as the difference between the amount of radiolabeled ligand bound in the absence of competitor and that bound in the presence of $1 \mu \mathrm{M}$ B or DM, respectively. The amount of specific binding in each case was (a) $135 \mathrm{fm} / \mathrm{mg}$ protein, (b) $118 \mathrm{fm} / \mathrm{mg}$ protein, (c) $191 \mathrm{fm} / \mathrm{mg}$ protein, and (d) $252 \mathrm{fm} / \mathrm{mg}$ protein. Each point is the mean of triplicate determinations; the SD was $<7 \%$ of the mean value for each point.

radioactive steroids. Cytosols were incubated with 10 $\mathrm{nM}{ }^{3} \mathrm{H}-\mathrm{B}$ or $10 \mathrm{nM}{ }^{3} \mathrm{H}-\mathrm{DM}$ in the presence of various concentrations of competitor. Competition for ${ }^{3} \mathrm{H}-\mathrm{B}$ binding sites in pituitary cytosol is shown in Fig. 3a; at a $10-\mathrm{nM}$ concentration of competitor the hierarchy of affinity is triamcinolone acetonide (TA) $>$ B $>$ DM $>$ ALDO $>\mathrm{P}$, while at higher concentrations $\mathrm{B}$ and $P$ are the most potent competitors, followed by DM and ALDO, while TA was least able to displace ${ }^{3} \mathrm{H}-\mathrm{B}$. This hierarchy at higher competitor concentrations is in contrast with that obtained when ${ }^{3} \mathrm{H}-\mathrm{DM}$ was used as ligand (Fig. 3b). Here the hierarchy (TA $=\mathrm{DM}$ $>\mathrm{B}>\mathrm{P}>\mathrm{ALDO}$ ) was identical to that previously reported for the classical ${ }^{3} \mathrm{H}$-DM binding glucocorticoid receptor of rat kidney and thymus cytosols $(11,19)$. The most striking distinction was obtained using TA as competitor; pituitary ${ }^{3} \mathrm{H}-\mathrm{DM}$ binding sites clearly show a high affinity for this steroid, although it has a very much lower affinity for ${ }^{3} \mathrm{H}$-B binding sites. These results confirm that whereas $B$ binds to classical glucocorticoid receptors, it also binds to sites that display a higher affinity for $B$ than for DM and TA, i.e., "B preferring" sites.

However, when the hormonal specificity of ${ }^{3} \mathrm{H}-\mathrm{B}$ and ${ }^{3} \mathrm{H}$-DM binding was analyzed in thymus cytosol (Fig. 3c, d), no difference in steroid specificity was seen, suggesting that in this tissue both ligands bind to a single class of sites, equivalent to those binding ${ }^{3} \mathrm{H}-\mathrm{DM}$ in pituitary cytosol.

Another characteristic examined was the sensitivity of the ${ }^{3} \mathrm{H}$-B binding sites to sulphydryl group reagents. The steroid-binding activities of receptors in general and glucocorticoid receptors in particular (20) have been shown to be sensitive to the state of reduction of sulphydryl groups. In contrast, CBG shows no such dependence (21). When the specific binding of ${ }^{3} \mathrm{H}-\mathrm{B}$ was determined at various concentrations of dithiothreitol (Fig. 4) the cytosol (but not the plasma) binding sites displayed a marked sensitivity toward the sulphydryl group reagent, confirming the nonidentity of the two species. The levels of ${ }^{3} \mathrm{H}$-DM specifically bound also showed a dependence on the concentration of dithiothreitol present. While the difference in cytosol ${ }^{3} \mathrm{H}-\mathrm{B}$ and ${ }^{3} \mathrm{H}-\mathrm{DM}$ binding appears considerable,

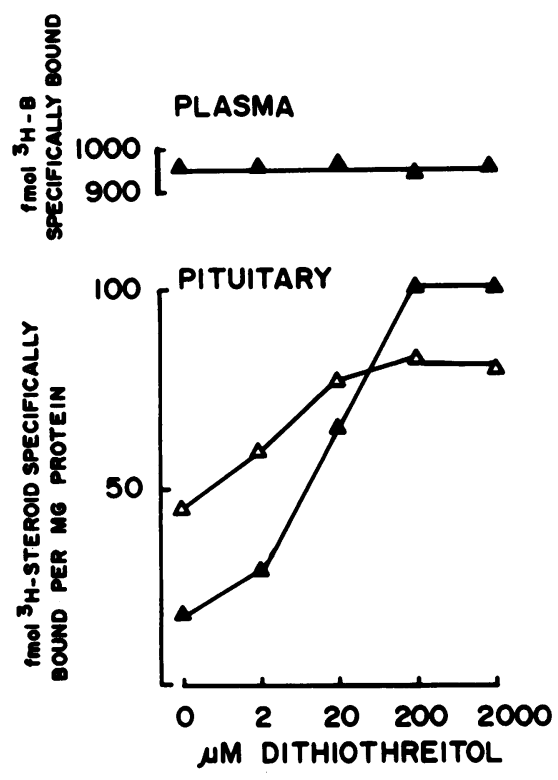

Figure 4 Sulphydryl group sensitivity of plasma and pituitary cytosol binding sites. Plasma (diluted 1:50 with TEMG buffer) containing various concentrations of dithiothreitol was incubated overnight at $4^{\circ} \mathrm{C}$ with $10 \mathrm{nM}{ }^{3} \mathrm{H}-\mathrm{B}$ with and without $1 \mu \mathrm{M} B$, and specific binding determined per $100-\mu \mathrm{l}$ aliquot. Pituitary cytosol $(100 \mu \mathrm{l})$ containing various concentrations of dithiothreitol was incubated under identical conditions with $10 \mathrm{nM}{ }^{3} \mathrm{H}-\mathrm{B}$ (closed triangles) or $10 \mathrm{nM}{ }^{3} \mathrm{H}-\mathrm{DM}$ (open triangles) with and without $1 \mu \mathrm{M} B$ or DM, and specific binding determined per milligram cytosol protein. Each point is the mean of triplicate determinations of total and nonspecific binding; the SD was $<5 \%$ of the mean value for each point. 
one interpretation is that it may merely reflect a differential stabilization of an identical binding site by the two ligands. An equally plausible hypothesis is that these differences reflect truly different characteristics of two nonidentical binding sites.

If there are in fact two separate classes of molecules differentially binding the radiolabeled ligands it should be possible, by the in vivo administration of one of the ligands, to preferentially occupy and presumably translocate one of the species into the cell nucleus. In Fig. 5 are shown the levels of specific ${ }^{3} \mathrm{H}-\mathrm{B}$ and ${ }^{3} \mathrm{H}$ DM binding in pituitary cytosol of rats injected $30 \mathrm{~min}$ before death with various concentrations of dexamethasone. This study is complicated by the fact that DM has appreciable affinity for the B-preferring site; despite this inevitable overlap, with increasing doses of dexamethasone the proportion of ${ }^{3} \mathrm{H}-\mathrm{DM}$ to ${ }^{3} \mathrm{H}-\mathrm{B}$ sites remaining in the cytosol progressively decreases. These results are consistent with DM preferentially occupying and translocating classic glucocorticoid receptors.

Given the mutually competitive nature of $B$ and DM for the two binding sites (Figs. 1 and 3), it is clear that

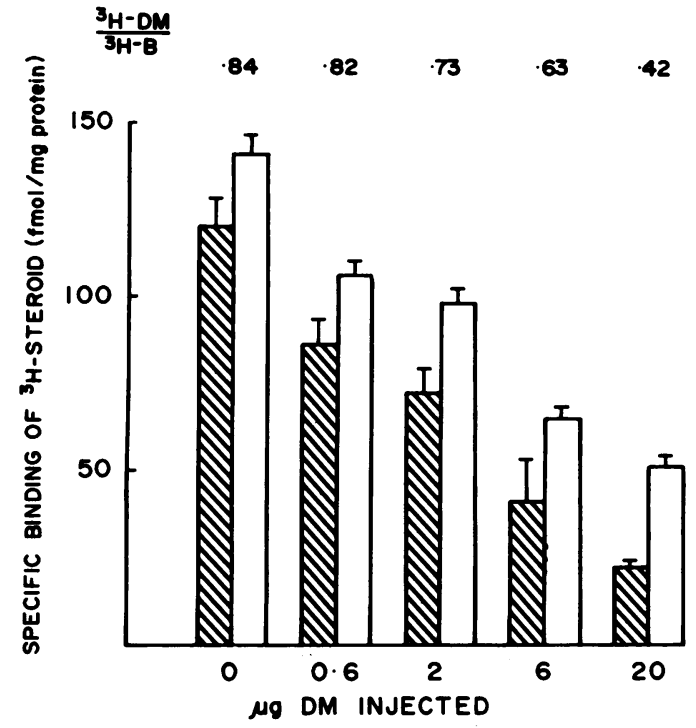

FIGURE 5 Selective occupancy/translocation of DM vs. B binding sites in pituitary cytosol, by in vivo administration of DM. Adrenalectomized rats were injected i.p. with 100 $\mu$ l vehicle alone $(0.9 \%$ saline), or with $100 \mu$ l vehicle containing increasing amounts of dexamethasone sodium phosphate, and killed 30 min later. Cytosols were prepared after treatment of the crude homogenate with dextran-coated charcoal. Specific binding was determined by incubation of cytosol with $10 \mathrm{nM}{ }^{3} \mathrm{H}-\mathrm{B}$ (open bars) or $10 \mathrm{nM}{ }^{3} \mathrm{H}-\mathrm{DM}$ (hatched bars), with and without $1 \mu \mathrm{M}$ equivalent nonradioactive competitor, at $4^{\circ} \mathrm{C}$ overnight. Each value is the mean of triplicates; error bars indicate SD. Superscript numbers show the ratio of ${ }^{3} \mathrm{H}-\mathrm{DM}$ to ${ }^{3} \mathrm{H}-\mathrm{B}$ binding at each concentration.

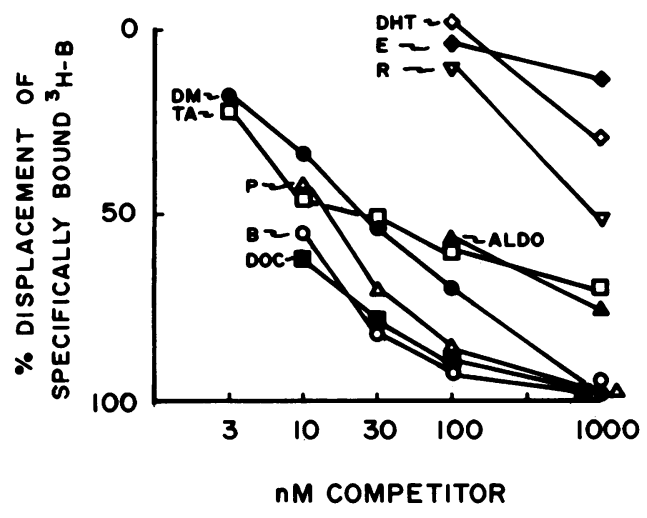

Figure 6 Steroid competition for ${ }^{3} \mathrm{H}$-B binding sites in pituitary cytosol after in vivo injection of dexamethasone. Adrenalectomized rats were injected with $20 \mu \mathrm{g}$ i.p. dexamethasone and the animals were killed 30 min later. Cytosols were prepared after treatment of the crude pituitary homogenates with dextran-coated charcoal. Steroid competition studies were performed as in Fig. 3; additional competitors used were deoxycorticosterone (DOC), promegestone ${ }^{\bullet}(R)$, estradiol $(E)$, and dihydrotestosterone (DHT). The amount of specific binding was $39 \mathrm{fm} / \mathrm{mg}$ protein. Each point is the mean of triplicates performed; the SD was $<8 \%$ of the mean value for each point. ${ }^{\circ} \mathrm{R}=17,21$-19-norpregna4,9-diene-3,20-dione.

in pituitary cytosol of adrenalectomized rats a proportion of the specifically bound ${ }^{3} \mathrm{H}-\mathrm{B}$ is to classical ${ }^{3} \mathrm{H}-\mathrm{DM}$ preferring glucocorticoid receptors. A more accurate estimate of the affinity and hormonal specificity of the B-preferring sites would then be expected where pituitary cytosol had been depleted of classical glucocorticoid receptors by the in vivo administration of DM. Such studies were thus performed in adrenalectomized rats injected with $20 \mu \mathrm{g}$ of DM $30 \mathrm{~min}$ before death. The hormonal specificity characteristics of ${ }^{3} \mathrm{H}-\mathrm{B}$ binding to such a cytosol are depicted in Fig. 6 . In comparison with the results obtained with untreated animals (Fig. 3a), P and B were now found to be far more potent competitors than DM, particularly at equivalent concentrations of ${ }^{3} \mathrm{H}-\mathrm{B}$ and competitor. The apparent affinity of ${ }^{3} \mathrm{H}-\mathrm{B}$ binding $\left(K_{\mathrm{d}} 4^{\circ} \mathrm{C} \sim 1\right.$ $n M)$ similarly was higher than in untreated animals. Not surprisingly, the structurally related compound DOC was found to be equipotent with $B$ in competing for ${ }^{3} \mathrm{H}$-B binding to the $B$ preferring site. These results are consistent with a relative increase of $B$ preferring sites over the glucocorticoid receptor in such pretreated rats. Promegestone, estradiol, and dihydrotestosterone displayed minimal affinity for the B preferring site, while TA and ALDO showed only modest affinity for ${ }^{3} \mathrm{H}-\mathrm{B}$ binding sites. The shape of the displacement curve for TA suggests that there may still be considerable heterogeneity in the remaining sites. This heterogeneity is probably not due to lack of de- 
pletion of "classic" glucocorticoid receptors, because similar displacement is seen in Fig. 3.

Finally, we established that the differences in binding of the two radioligands were not due to differences in steroid metabolism. When the ${ }^{3} \mathrm{H}$-steroids, incubated overnight in pituitary cytosol, were extracted in dichloromethane/methanol they were found to be essentially unmetabolized ( $97 \%$ authentic) by thinlayer chromatography analysis.

\section{DISCUSSION}

The series of experiments reported here provide strong evidence that there exists in the anterior pituitary gland of the rat sites that bind B with higher affinity than do the classical glucocorticoid receptors. We have tentatively termed these the B-preferring sites, and have shown that they differ from previously described nonclassical glucocorticoid binding sites (6-8). Differentiation from classical glucocorticoid receptors has been achieved on the basis of steroid specificity, and the preferential occupation and nuclear translocation of classical glucocorticoid receptors by the in vivo administration of DM. The B-preferring sites, which sediment at $\sim 8 S$ during ultracentrifugation through low ionic strength sucrose gradients, are clearly different from the type III receptors, which sediment at $4 \mathrm{~S}$ under similar conditions (16). The ability of DM at high concentrations to completely suppress ${ }^{3} \mathrm{H}-\mathrm{B}$ binding to the B-preferring site (Fig. 6) is also inconsistent with the reported specificity of the type III (CBG-like) binding site, as is the difference in sulphydryl group dependence. These criteria similarly serve to distinguish the B-preferring sites from CBG.

Identity of the B-preferring species with other steroid receptors is excluded on the basis of the hormonal specificity studies performed in Fig. 6. Classic mineralocorticoid receptors in either kidney (22) or pituitary (23) show a higher affinity for aldosterone than DM $(22,23)$, which these sites clearly do not; progesterone, estrogen, and androgen receptors appear excluded on the basis of the negligible competition for ${ }^{3} \mathrm{H}-\mathrm{B}$ sites displayed by promegestone, estradiol, and dihydrotestosterone, respectively (Fig. 6). We have additionally confirmed that the B-preferring site is unrelated to the progesterone receptor, by using AP from 1-wk ovariectomized/adrenalectomized rats (results not shown), where the pituitary content of progesterone receptor has been shown to be an order of magnitude less than in animals with intact gonads (24).

Several other studies have demonstrated that in the AP of the rat ${ }^{3} \mathrm{H}-\mathrm{B}$ binds to at least two intracellular binding sites $(5,25,26)$ as well as a plasma membrane binding site (6). The additional sites distinct from the classical glucocorticoid receptor, however, have been identified with either the intracellular type III recep- tor or extracellular CBG-like binding proteins. In AtT20/D-1 cells, a mouse pituitary tumour cell line, $B$ and DOC have been found to compete for binding to ${ }^{3} \mathrm{H}$ TA binding sites with higher potency than DM, but lower than TA (15), a specificity clearly different from that obtained for ${ }^{3} \mathrm{H}$-B preferring sites in the present study, and from classical ${ }^{3} \mathrm{H}-\mathrm{DM}$ binding glucocorticoid receptors.

An additional characteristic of the B-preferring sites that we observed was the apparent high rate of dissociation of ${ }^{3} \mathrm{H}-\mathrm{B}$ from such sites. A rapid dissociation rate is consistent with the studies of McEwen et al. $(4,5)$, who showed that after in vivo administration of ${ }^{3} \mathrm{H}-\mathrm{B}$ very little nuclear retention was seen. In addition, this may explain why ${ }^{3} \mathrm{H}-\mathrm{P}$ and ${ }^{3} \mathrm{H}-\mathrm{DOC}$ similarly showed minimal pituitary localization (4), despite the fact that $P$ has been shown to have a rapid and potent suppressor effect on ACTH release in rat anterior pituitary gland (1), and from mouse pituitary tumor cells in culture (9). Such an activity is in marked contrast to the well known antiglucocorticoid properties of $P$ (10-14), but is supported by studies of $\beta$ endorphin production where both $\mathrm{P}$ and DOC show what appears to be full glucocorticoid agonist properties (27).

From the data presented in this paper it would appear that corticosterone, the physiological glucocorticoid in rats, may bind to two distinct types of glucocorticoid receptor in the anterior pituitary. One of these is the classical, ${ }^{3} \mathrm{H}-\mathrm{DM}$ binding glucocorticoid receptor found in thymus, and other glucocorticoid target tissues; the other is distinct from not only classical glucocorticoid receptors, but also from the previously reported CBG-like intracellular binders. Whether or not such B-preferring sites represent physiological steroid receptors awaits further evidence including that of a direct correlation between binding and a specific cellular effect. The rapid suppression of ACTH secretion by $B, P$, and DOC $(3,9)$, and the high affinity of these steroids for these novel B-preferring sites is consistent with a role for such sites in modulating the rapid release of ACTH. Currently, studies are in progress in this laboratory to examine such a possibility.

\section{ACKNOWLEDGMENT}

This work was supported by the National Health and Medical Research Council of Australia.

\section{REFERENCES}

1. Jones, M. T., B. Gillham, S. Mahmoud, and M. C. Holmes. 1979. The characteristics and mechanism of action of corticosteroid negative feedback at the hypothalamus and anterior pituitary. In Interaction within the Brain-Pituitary-Adrenocortical System. M. J. Jones, 
B. Gillham, M. F. Dallman, and S. Chattopadhyay, editors. Academic Press, Inc., London, England. 163-180.

2. Fehm, H. L., K. H. Voigt, G. Kummer, R. Lang, and E. F. Pfeiffer. 1979. Differential and integral corticosteroid feedback effects on ACTH secretion in hypoadrenocorticism. J. Clin. Invest. 63: 247-253.

3. Jones, M. T., and E. W. Hillhouse. 1976. Structure activity relationship and the mode of action of corticosteroid feedback on the secretion of corticotrophin-releasing factor (corticoliberin). J. Steroid Biochem. 7: 11891202.

4. McEwen, B. S., R. DeKloet, and G. Wallach. 1976. Interactions in vivo and in vitro of corticoids and progesterone with cell nuclei and soluble macromolecules from rat brain regions and pituitary. Brain Res. 105: 129-136.

5. DeKloet, R., G. Wallach, B. S. McEwen. 1975. Differences in corticosterone and dexamethasone binding to rat brain and pituitary. Endocrinology. 96; 598-609.

6. Koch, B., B. Lutz, B. Bucher, B. Briaud, and C. Mialhe. 1978. Specific interaction of corticosteroids with binding sites in the plasma membranes of the rat anterior pituitary gland. J. Endocrinol. 79: 215-222.

7. DeKloet, R., P. Burbach, and G. Mulder. 1977. Localization and role of transcortin-like molecules in the anterior pituitary. Mol. Cell Endocr. 7: 261-273.

8. Koch, B., B. Lutz-Briand, and C. Mialhe. 1976. Heterogeneity of pituitary glucocorticoid binding: evidence for a transcortin-like compound. Biochim. Biophys. Acta. 444: 497-507.

9. Johnson, L. K., N. L. Eberhardt, S. S. Spindler, J. A. Martial, M. F. Dallman, M. T. Jones, and J. D. Baxter. 1980. Regulation of the genes for ACTH and growth hormone by glucocorticoid hormones. In Endocrinology 1980. Australian Academy of Science, Elsevier. 70-73.

10. Rousseau, G. G., J. D. Baxter, and G. M. Tomkins. 1972. Glucocorticoid receptors: relationship between steroid binding and biological effects. J. Mol. Biol. 67: 99-116.

11. Munck, A. and Wira, C. 1971. Glucocorticoid receptors in rat thymus cells. In Advances in the Biosciences. No. 7. Schering Workshop on Steroid Hormone Receptors. G. Raspe, editor. Pergamon Press, Oxford, England. 301-324.

12. Baxter, J. D., A. W. Harris, G. M. Tomkins, and M. Cohn. 1971. Glucocorticoid receptors in lymphoma cells in culture: relationship to glucocorticoid killing activity. Science (Wash., DC). 171: 189-191.

13. Naylor, P. H., S. S. H. Gilani, R. J. Milholland, and F. Rosen. 1980. Antiglucocorticoids: in vivo assay and evaluation of cortexolone, progesterone and 6 - $\beta$-bromoprogesterone. Endocrinol. 107: 117-121.

14. Duncan, M. R., and G. R. Duncan. 1979. An in vivo study of the action of antiglucocorticoids on thymus weight ratio, antibody titre and the adrenal-pituitary hypothalamus axis. J. Steroid Biochem. 10: 245-259.
15. Harrison, R. W., S. Fairfield, and D. N. Orth. 1976. Multiple glucocorticoid binding components of intact AtT-20/D-1 mouse pituitary tumour cells. Biochim. Biophys. Acta 444: 487-496.

16. Feldman, D., J. W. Funder, and I. S. Edelman. 1973. Evidence for a new class of corticosterone receptors in the rat kidney. Endocrinology. 93: 1429-1441.

17. Bradford, M. 1976. A rapid and sensitive method for the quantitation of microgram quantities of protein utilizing the principle of protein-dye binding. Anal. Biochem. 72: 248-254

18. Seal, U. S., and R. P. Doe. 1962. Corticosteroid binding globulins. I. Isolation from plasma of diethylstilbestrol treated men. J. Biol. Chem. 237: 3136-3140.

19. Funder, J. W., D. Feldman, and I. S. Edelman. 1973. Glucocorticoid receptors in rat kidney: the binding of tritiated Dexamethasone. Endocrinology. 92: 1005-1013.

20. Granberg, P. J., and P. L. Ballard. 1977. The role of sulphydryl groups in the binding of glucocorticoids by cytoplasmic receptors of lung and other mammalian tissues. Endocrinology 100: 1160-1168.

21. Muldoon, T. G., and U. Westphal. 1967. Steroid protein interactions. XV Isolation and characterizations of corticosteroid-binding globulin from human plasma. J. Biol. Chem. 242: 5636-5644.

22. Funder, J. W., D. Feldman, and I. S. Edelman. 1973. The roles of plasma binding and receptor specificity in the mineralocorticoid action of aldosterone. Endocrinology. 92: 994-1004.

23. Krozowski, Z. S., and J. W. Funder. 1981. Mineralocorticoid receptors in rat anterior pituitary: toward redefinition of 'mineralocorticoid hormone'. Endocrinology. 109: 1221-1224.

24. Maclusky, N. J., and B. S. McEwen. 1978. Oestrogen modulates progestin receptor concentrations in some rat brain regions but not in others. Nature (Lond.). 274: 276-278.

25. DeKloet, R., and B. S. McEwen. 1976. A putative glucocorticoid receptor and transcortin-like macromolecule in pituitary cytosol. Biochim. Biophys. Acta. 421: 115123.

26. Macluskey, N. J., B. B. Turner, and B. S. McEwen. 1977. Corticosteroid binding in rat brain and pituitary cytosols: resolution of multiple binding components by polyacrylamide gel based electrofocusing. Brain Res. 130: 564-571.

27. Vale, W., J. Rivier, R. Guillemin, and C. Rivier. 1979. Effects of purified CRF and other substances on the secretion of ACTH and $\beta$-endorphin-like immunoactivities of cultured anterior or neurointermediate pituitary cells. In Central Nervous System Effects of Hypothalamic Hormones and other Peptides. R. Collu, A. Barbeau, J. Ducharme, and J. G. Rochefort. Raven Press, New York. 163-176. 